\title{
Allozyme differentiation between Baltic and North Sea Mytilus populations: a reassessment of evidence from transplantations
}

\author{
Risto Väinölä
}

Department of Genetics, University of Helsinki, Arkadiankatu 7, SF-00100 Helsinki, Finland

\begin{abstract}
Data on dramatic genetic changes associated with strong mortality in mussels reciprocally transplanted between Baltic (low salinity) and North Sea environments were presented by Johannesson et al. (1990; Mar Ecol. Prog. Ser. 59: 211-219) as evidence for selection at the studied allozyme loci, and as a challenge to the view that the extensive differentiation between native Baltic and North Sea mussel populations reflects an ancient divergence of 2 phylogenetic lineages. However, a reassessment of the data shows that the transplanted mussel batches could not have contained the genetic variation needed to yield the observed 'selection responses'. The surviving mussels seem to have represented local contamination in the experimental lots, and the results are thus non-informative for evaluating the adaptive nature and historical background of the distinctive allozyme differentiation in this case.
\end{abstract}

The Baltic and North Sea populations of the common mussel, until recently treated as taxonomically identical (Mytilus edulis L.), are strongly differentiated with respect to about half of their allozyme genes (e.g. Väinölä \& Hvilsom 1990). Conflicting interpretations have been presented on the evolutionary background and systematic significance of this divergence. Theisen (1978) and Bulnheim \& Gosling (1988) suggested that the genetic differences are due to a direct adaptive response to the strong environmental difference between the seas, and are thus of a post-glacial origin (maximum 7000 to $8000 \mathrm{yr}$ ). By contrast, we have argued that they reflect an existence of 2 anciently diverged lineages now meeting in a secondary contact zone (Väinölä 1985, Varvio et al. 1988, Väinölä \& Hvilsom 1990); the observed allozymes are regarded as markers of integrated (coadapted) gene complexes, which are maintained through selection against hybrids, irrespective of the environment. This view is supported by the close similarity of the Baltic mussel stock with a recently discovered taxon, $M$. trossulus Gould, which occurs on both the Atlantic and Pacific coasts of North America along with populations ascribed to $M$. edulis and $M$. galloprovincialis Lmk (Varvio et al. 1988, McDonald \& Koehn 1988). A full specific status for the 3 mussel types was suggested by McDonald \& Koehn (1988), whereas Väinölä \& Hvilsom (1990) preferred a semispecies rank: in the contact areas, all the taxa commonly interbreed and thus do not meet the biological species criterion.

In a series of papers, Kautsky et al. (1990), Johannesson et al. (1990) and Tedengren et al. (1990) recently considered the background of differences between the Baltic and North Sea mussels on the basis of reciprocal transplantation experiments. Many of the phenotypic differences in the 2 environments, such as in growth rate and some metabolic parameters, were found to be environmentally induced, but others (including some shell characteristics, ammonium excretion, metabolic efficiency) obviously also had a genetic component (Kautsky et al. 1990, Tedengren et al. 1990). As regards allozyme differences, allele frequencies at 2 strongly differentiated loci ( $P g i$ and $P g m$ ) were reported to have dramatically changed after catastrophic mortality events in transplanted mussel batches; the survivors were essentially similar to the native mussels at the target sites. This was interpreted as an indication of direct selection at the allozyme loci, which would have invalidated the value of these characters as phylogenetic and taxonomic markers, and questioned the ancient background of the differentiation in general (Johannesson et al. 1990).

In the present paper, the data of Johannesson et al. (1990) are re-examined, and it is argued that they are inconsistent with the claim of locus-specific selection and provide no evidence against a systematic interpretation of the allozyme divergence. It is shown that the transplanted mussel batches could not have contained sufficient genetic diversity to yield the observed selection responses; the survivors probably represented local contamination among the transplanted mussels. 
Reassessment of transplantation data. In the experiments of Johannesson et al. (1990), 22 out of 600 mussels transplanted from the North Sea area (Tjärnö, Skagerrak, 20 to $30 \%$ S) survived a gradual acclimatization to the Baltic salinity ( 6 to $7 \%$ S); there was no further mortality in nature during the next 20 mo. The survivors were reported to be similar to the local Baltic mussels (Askö, central east Sweden) at $P_{g i}$ and intermediate at $P_{g m}$. On the other hand, there was no significant mortality in 40000 mussels transplanted reciprocally to the North Sea, until 16 mo later, when $99.5 \%$ of them suddenly died, possibly due to a disease; the survivors, harvested after another $11 \mathrm{mo}$, had allele frequencies similar to those of local North Sea mussels at both loci.

Genotype frequencies were not presented, but the following inferences, based on the allele frequency data given, are made in a conservative vein with regard to the present argument. First, the Pgi locus alone will be examined. The local (source) populations are assumed to have been in Hardy-Weinberg (HW) equilibrium; this structure has been documented for Pgi in extensive material from the Baltic by Väinölä (1985), and no significant deviations were found by Johannesson et al. (1990).

Table 1 reproduces the essential data, condensed to a synthetic 2 -allele system; alleles 4 and 5 of Johannesson et al. are combined to a 'typical Baltic' allele B (98' in Väinölä \& Hvilsom 1990); the remaining morphs 1 to 3 constitute allele $N$, typical of the North Sea area. The 22 survivors of the North Sea mussels were exclusively of the BB type. From the estimated frequency of $B$ at the source site, the expected number of $B B$ homozygotes among all the transplants would be $0.16^{2} \times 600=$ 15.4. Even if we allow for sampling errors, this would imply that the selection was exclusively based on the Pgi phenotype: practically all the BB homozygotes, and no others, survived (indeed, this would have been the most striking demonstration of fitness dominance at an allozyme locus so far; about 160 heterozygotes with the $B$ allele would all have died). However, the mortality was heavily related to size: while the mean length of transplanted mussels was $20 \mathrm{~mm}$ (range 1 to 40), that of the survivors was $2.0 \mathrm{~mm}$ (range 1 to 4 ). If genotype was independent of size, this size class would have initially contained only a couple of BB individuals.

Among the 200 mussels surviving from the batch transplanted from the Baltic to the North Sea (estimated B frequency 0.13 ), 74 to $87 \%$ (148 to 174 individuals) must have lacked the $B$ allele, thus being $N N$ homozygotes. The frequency of these homozygotes in the Baltic population should have been at least $0.37 \%$ to provide the minimum $148 \mathrm{NN}$ individuals to the sample batch of 40000 transplants; this genotype frequency is expected (under HW) from a $\mathrm{N}$ allele frequency of 0.06 . The observed allele frequency in 161 'non-selected' Baltic mussels studied by Johannesson et al. was 0.003 (i.e. one heterozygote seen); another available estimate, based on 303 individuals from within $75 \mathrm{~km}$ of the Baltic site of Johannesson et al., is 0.008 (Väinölä 1985). From these frequencies, only 0.4 to 2.6 homozygotes would be expected to be included in a sample of 40000 from a HW population. Or, viewed in another way, a batch of at least 15 million, or 2.3 million mussels, respectively, would have been required to provide $74 \% \mathrm{NN}$ homozygotes among 200 survivors.

It is thus evident even from a single locus examination that the observed numbers of survivors in either experiment could not have been present among the given numbers of transplanted mussels sampled from the source populations, or even in samples several times larger; selection among genotypes within the set of transplanted mussels cannot account for the results. The conclusion would be still stronger if 2-locus genotypes were considered (cf. below). An obvious explanation would be that the survivors (mostly) represented contamination of the transplanted batches by

Table 1. Mytilus edulis complex. Pgi allele frequencies in mussels from the North Sea area (TJ and other nearby sites) and the Baltic (AS), and in surviving transplanted mussels (TJ $\rightarrow$ AS and AS $\rightarrow$ TJ). Data for native mussels are pooled from subsamples from different years; for the AS mussels, these represent mainly transplanted mussels before any considerable mortality. Data condensed from Table 2 in Johannesson et al. (1990)

\begin{tabular}{|c|c|c|c|c|c|}
\hline & \multicolumn{3}{|c|}{ Native } & \multicolumn{2}{|c|}{ 'Transplanted', after mortality } \\
\hline & $\begin{array}{c}\text { TJ } \\
\text { (North Sea) }\end{array}$ & $\begin{array}{l}\text { Other North } \\
\text { Sea sites }\end{array}$ & $\begin{array}{c}\text { AS } \\
\text { (Baltic) }\end{array}$ & $\mathrm{TJ} 84^{\circ} \rightarrow \mathrm{ASS}$ & $\mathrm{AS}^{\circ} 6^{\circ} \rightarrow \mathrm{TJ}$ \\
\hline Allele ${ }^{a}: N$ & 0.84 & 0.82 & 0.003 & - & 0.87 \\
\hline B & 0.16 & 0.18 & 0.997 & 100 & 0.13 \\
\hline Sample size & 211 & 471 & 161 & 22 & 74 \\
\hline Total transplants & & & & 600 & 40000 \\
\hline Survivors $(\%)$ & & & & $22(3.7 \%)$ & $200(0.5 \%)$ \\
\hline
\end{tabular}


local (target site) mussels, and the mortality was selective by origin (which is reflected in the genotypes). In the Baltic-to-North Sea experiment, the transplanted mussels ( 1 yr old), attached to a rope, were suspended side-by-side with native North Sea mussels at $9 \mathrm{~m}$ depth', 'where settling rate is generally very low' (Tedengren et al. 1990. Johannesson et al. 1990). The culture was guarded by removing newly metamorphosed larvae during the first 3 mo, but not subsequently; obviously, a possibility of later larval recruitment or secondary settlement by drifting local mussles cannot be ruled out. The chances of contamination in the reciprocal experiment are more difficult to evaluate, as the $96 \%$ mortality took place in the laboratory during initial acclimatization to reduced salinity; the confinement of survival to the very smallest individuals is notable, however.

Based on material from the same experiments Kautsky et al. (1990) and Tedengren et al. (1990) noted that some morphological and physiological differences of the Baltic and North Sea stocks were retained for at least a year when Baltic mussels had been transferred to the North Sea habitat, which was taken to indicate a genetic basis for the differences. The origin of the mussels should thus be recognizable also on these grounds. However, no information on these traits was given on mussels surviving the mass mortality events in either transplantation; such data could have elucidated the origin of survivors.

The differential survival of genotypes within the transplanted batches was the main basis for questioning the value of the allozyme differentiation as an indicator of an ancient divergence and integrated systematic nature of the Baltic and North Sea mussel stocks; as the results now seem to be artefactual, they should be irrelevant in this discussion. On the other hand, the data and conclusions of Johannesson et al. (1990) appear to be inconsistent even under their own assumption of selection among genotypes of a single origin; from that premise, the results should rather have been taken to support the systematic interpretation.

To illustrate this, suppose that the discrepancies were not due to contamination but to gross errors ( 1 to 2 orders of magnitude) in estimates of some of the initial parameters (transplant numbers, gene frequencies, genotypic structure), and the allele frequency changes at Pgi were caused by an exceptionally accurate, dominant selection among genotypes. The background of differences at other loci would remain to be explained. In the transplant to the North Sea, Pgm frequencies also 'changed' to conform with the local structure. As recognized by Johannesson et al., this would imply strong (almost complete) interlocus disequilibrium in the source population; otherwise the batch should still have been several orders greater. The loci recombine freely (Hvilsom \& Theisen 1984), and a maintenance of such disequilibrium in a local randomly mating population would require strong epistatic selection (viability superiority of the order $10^{2}$ ) favouring the typical North Sea genotypes (synthetic double homozygote) in the Baltic environment (and vice versa); on the other hand, a main claim of the authors was strong selection against the particular genotypes in the same environments in the reciprocal experiments.

As an alternative mechanism generating the disequilibrium, direct larval transport from one sea area to the other (population mixing) might be invoked. With regard to discerning the effects of single loci from selection on the general genetic (taxonomic) background, this hypothesis is similar to that of the posttransplant contamination proposed above. Moreover, at least from the North Sea (Kattegat/Belt Sea) to the Baltic, transport would seem extremely unlikely; a considerable part (ca $0.5 \%$ ) of the sampled Baltic population would have to have migrated over $500 \mathrm{~km}$, against the main current, and, once again, in the environment found to be fatal for their genotype.

With a larger set of loci, the case becomes even more compelling. Studies reporting another 4 strongly differentiated loci were cited by Johannesson et al.; Väinölä \& Hvilsom (1990) recorded differentiation at 12 out of 22 loci, and the actual number may be in hundreds or thousands. We may consider 2 extreme situations. If the loci were generally not in disequilibria in the native populations, an observation of accurate selection saving one entire genotype class at 1 (or 2 associated) loci would rule out any selective effects in these experiments at the remaining great majority of differentiated loci (at least within the surviving class). On the other hand, if selective mortality occurred also at the other unstudied loci, they should all have been in strong disequilibria within the native populations. The maintenance of such widespread associations among largely unlinked loci even in parapatry is actually the essential basis for the argument of the systematic nature of the discussed mussel types, and a maintenance in sympatry would certainly strengthen this claim; however, as there seems to be little or no prezygotic isolation between the 2 mussel types (Väinölä \& Hvilsom 1990), such (local) selection would imply an unbearable genetic load even with a few loci. On the other hand, if the disequilibria were caused by mixing of differentiated (Baltic and North Sea) populations, we would again be dealing with the case of natural contamination', with the inconsistencies pointed out above.

In general, the discussed case of misinterpretation should emphasize the importance of basing conclusions on population genetic phenomena (such as selec- 
tion) on direct examination of the observed data (here, 2-locus genotype frequencies) rather than on marginal summary statistics (allele frequencies); a direct approach would permit an evaluation of the magnitude of the postulated forces and an immediate identification of instances where other explanations are required. In the transplantation experiments, the extreme allele frequencies exceptionally allowed a partial reconstruction of the underlying genotype frequencies and a confident exclusion of selection as the factor accounting for the results. In other cases of differentiation (local, temporal) attributed to selection in the study of Johannesson et al. (1990), such reconstructions are not feasible; however, even those data suggest that viability differences among genotypes would have been improbably large in order to yield the reported allele frequency differences, and claims of selection remain unsubstantiated until a proper evaluation of the genotypic data. More conceivably, the differences might be ascribed to occasional allele misassignments in data gathered over several years, promoted by the intricate dependence of allozyme separation on experimental condition in Mytilus (Beaumont \& Beveridge 1983, Väinölä \& Hvilsom 1990).

\section{LITERATURE CITED}

Beaumont, A. R., Beveridge, C. M. (1983). Resolution of pholphoglucomutase isozymes in Mytilus edulis L. Mar Biol. Lett. 4: 97-103

Bulnheim, H.-P., Gosling, E. (1988). Population genetic struc- ture of mussels from the Baltic Sea. Helgoländer Meeresunters. 42: 113-129

Hvilsom, M. M., Theisen, B. F. (1984). Inheritance of allozyme variations through crossing experiments with the blue mussel, Mytilus edulis L. Hereditas 101: 1-7

Johannesson, K., Kautsky, N., Tedengren, M. (1990). Genotypic and phenotypic differences between Baltic and North Sea populations of Mytilus edulis evaluated through reciprocal transplantations. II. Genetic variation. Mar. Ecol. Prog. Ser. 59: 211-219

Kautsky, N., Johannesson, K., Tedengren, M. (1990). Genotypic and phenotypic differences between Baltic and North Sea populations of Mytilus edulis evaluated through reciprocal transplantations. I. Growth and morphology. Mar. Ecol. Prog. Ser. 59: 203-210

McDonald, J. F., Koehn, R. K. (1988). The mussels Mytilus galloprovincialis and $M$. trossulus on the Pacific coast of North America. Mar. Biol. 99: 111-118

Tedengren, M., André, C., Johannesson, K., Kautsky, N. (1990). Genotypic and phenotypic differences between Baltic and North Sea populations of Mytilus edulis evaluated through reciprocal transplantations. III. Physiology. Mar. Ecol. Prog. Ser. 59: 221-227

Theisen, B. F. (1978). Allozyme clines and evidence of strong selection in three loci in Mytilus edulis L. (Bivalvia) from Danish waters. Ophelia 17: 135-142

Väinölä, R. (1985). Sinisimpukan geenifrekvenssivaihtelu Itämeressä (Gene frequency variation in Baltic mussel populations). M. Sc. thesis, Dept of Genetics, Univ, of Helsinki

Väinölä, R., Hvilsom, M. M. (1990). Genetic divergence and a hybrid zone between Baltic and North Sea Mytilus populations (Mytilidae; Mollusca). Biol. J. Linn. Soc. (in press)

Varvio, S.-L., Koehn, R. K., Väinölä, R. (1988). Evolutionary genetics of the Mytilus edulis complex in the North Atlantic region. Mar. Biol. 98: 51-60

Manuscript received: May 17, 1990 